\title{
Designing for reintermediation in the brick-and-mortar world: Towards the travel agency of the future
}

\author{
Jasminko Novak • Gerhard Schwabe
}

Received: 31 August 2008 / Accepted: 9 December 2008 / Published online: 6 February 2009

(C) Institute of Information Management, University of St. Gallen 2009

\begin{abstract}
The Internet and electronic marketplaces have profoundly transformed the travel services industry and challenged the traditional value proposition of travel agencies: What is the reason for their existence if information is abundantly available and transactions can be flexibly conducted in direct buyer-seller interactions on the Internet? Traditional travel agencies are struggling to develop new value propositions which differentiate them against the Internet competition, largely based on expanding their reach through online subsidiaries. We present a reintermediation approach based on a novel way of ITenabled travel advisory which integrates the advantages of interactive technologies and Internet channels with the advantages of direct customer interaction in the physical agency setting. In particular, we propose a reintermediation framework based on the integration of kernel theories from information seeking behavior, interactive value creation, relationship marketing and the design of hedonic information systems. We argue that physically collocated travel advisory services can create a significant added value, if
\end{abstract}

Responsible editor: Rolf T. Wigand

This is a fundamentally revised and significantly extended version of our paper presented at the 21 st Bled eConference on eCollaboration (Schwabe, Novak and Aggeler, 2008).

The authors appear in alphabetical order. Both have equally contributed to this paper.

J. Novak $(\bowtie) \cdot$ G. Schwabe

Department of Informatics, Information Management Research

Group, University of Zurich,

Binzmühlestr 14,

CH-8050 Zurich, Switzerland

e-mail: novak@ifi.uzh.ch

G. Schwabe

e-mail: schwabe@ifi.uzh.ch they succeed in uncovering customers' hidden needs, heightening trust and relationship building in the advisory process and creating a better user experience. Following the design science methodology we validate the proposed framework through the design, implementation and evaluation of a proof-of-concept prototype in a field experiment in a real-world travel agency.

Keywords Reintermediation · Design-science .

Travel advisory · e-Tourism · CSCW - Large display ·

Advisory support · User experience · Value co-creation

\section{JEL Classification L83}

\section{Introduction}

The widespread use of the Internet and electronic marketplaces together with increased competition and changing customer needs have fundamentally transformed the travel services industry. While tourism has been a booming industry and the best selling category on the Internet (Anckar, 2003), traditional tourist agencies are increasingly struggling to survive and avoid the threat of disintermediation: the bypassing of their role as travel service intermediary (Dilts and Prough, 2002). New competitors have undermined their traditional business model (Buhalis, 2002) with a large number of travel transactions and services (e.g. booking flights or hotels) having moved to the Internet.

Different authors have pointed out the need for travel agencies to reposition their value propositions and to provide greater value-added services based on the integration of Internet technologies and new marketing strategies (Dilts and Prough, 2002). Thereby, most approaches tend to focus on using technology to expand the reach of traditional travel agencies through an associated Internet platform and 
its online services (e.g. online booking, travel communities, e-CRM; see Dilts and Prough, 2002; Werthner and Ricci, 2004 for an overview). In contrast, the possibilities for using novel technologies to provide value-added services in the brick-and-mortar travel office by exploiting its main point of advantage - the direct and individual contact with the customer-have been little considered.

In this paper we consider this gap by addressing the following research questions: How can traditional travel agencies develop a reintermediation strategy which builds upon physically collocated agent-customer interaction for the development of unique added-value propositions? How can such a strategy be realized through the development and use of innovative information systems?

The paper is organized as follows. We start by describing our research method (Fig. 1) based on design-science (Hevner et al., 2004) and the piloting approaches (Witte, 1997, Schwabe and Krcmar, 2000), followed by an analysis of the problem space. We then derive a solution model in form of a theoretically founded reintermediation framework for collocated travel advisory and associated requirements for its instantiation into concrete information systems. In order to validate the framework we show how it has been implemented in a concrete prototype system, evaluated in a controlled field experiment in a real-world travel office. We conclude by discussing to which extent this supports the internal and external validity of the proposed reintermediation framework and its implications for informing the implementation of effective reintermediation strategies in practice.

\section{Research method}

In this work, we adopt the design-science approach which aims at developing solutions to organizational and business problems through the design and evaluation of novel artifacts (Hevner et al., 2004). Complementary to behavioral science which develops and verifies theories explaining human and organizational phenomena in information system use and development, the goal of design-science research is "to develop technology-based solutions to important and relevant business problems" (ibid.). To achieve this, design-science focuses on the creation of innovative artifacts (new constructs, models, methods or prototype systems ) which allow organizations to act in new ways in solving problems effectively and achieving their goals (ibid.). The design process is thereby informed by existing theories which are applied and extended through problem-solving and the creative intuition of the researcher (Markus et al., 2002, Hevner et al., 2004). Hence, the design and evaluation of IT artifacts useful for solving a particular problem situation is a means to the development of scientific knowledge advances, especially in areas in which existing theories are insufficient or have not yet been successfully applied in a required configuration (Hevner et al., 2004).

Accordingly, in developing a solution to the challenging problem of reintermediation strategies which allow traditional travel agencies to assert themselves against the Internet competition, we proceed as follows. First, we analyze the problem environment by considering the market pressures and organizational constraints inducing the disintermediation threat for traditional travel agencies. Based on this analysis we identify opportunities for the development of effective solutions and relate them to existing theoretical contributions from information seeking behavior, interactive value creation, relationship marketing and the design of hedonic information systems. Building upon this literature as kernel theories (ibid.) we propose a reintermediation framework for collocated travel advisory as a concrete solution model for the described problem situation.

In order to validate the framework we derive metarequirements (Walls et al., 1992) for the design of concrete information systems implementing the proposed model into practice and present a concrete instantiation in form of a proof-of-concept prototype. The design and implementation of the prototype system plays a dual role in our methodological approach. On the one hand, it serves as a vehicle for verifying the internal validity of the proposed reintermediation framework: by successfully implementing a proof-ofconcept prototype based on requirements of the proposed framework we can show that the synthesis of proposed solution elements into a functioning system is possible. This demonstrates that the integration of the proposed elements of kernel theories is possible in a non-contradictory way. This method of synthetic evaluation corresponds to the piloting methodology described in (Witte, 1997).
Fig. 1 Research method: design of an innovative solution framework and its validation through synthesis in a proof-ofconcept prototype
Solution Framework

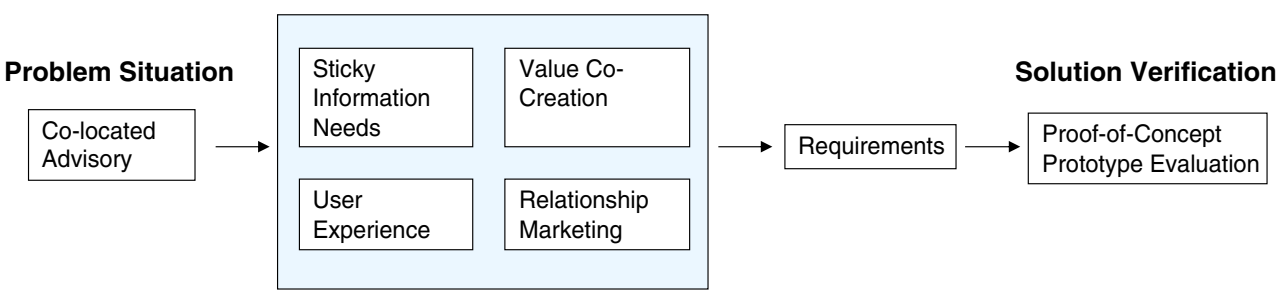


This method is suitable for evaluation of innovations whose realization and effects depend on a complex sociotechnical setting in which a number of variables interact with each other and cannot be isolated in classical causeeffect relations. In such cases, evaluating prototype systems representing concrete instantiations of a solution model in a real-world context allows us to draw two kinds of "if-then" conclusions. First, it can be shown that if the effecting variables describing the problem context and the components of the socio-technical system are combined in an appropriate way, the realization of the proposed innovation is possible. Second, it can be shown that if the proposed innovation is realized, it induces technological consequences in form of a specific form of use, a specific economic efficiency or a specific societal impact (ibid.).

On the other hand, by evaluating the prototype against the requirements of the proposed reintermediation framework we can show to which extent its given instantiation is suitable for its implementation in practice. This provides both actionable knowledge in form of a usable artifact for applying the solution framework in practice (cf. utility as goal criterion for design-science research (Hevner et al., 2004)) as well as input for the next research and design cycle. This provides verifiable contributions in the areas of the design artifact (the solution framework and its instantiation) and design foundations (relevance of selected kernel theories to the problem situation) (ibid).

In developing a concrete instantiation of the proposed framework we followed the user-centred design approach which is based on an iterative process of requirements specification, design and user feedback (ISO 13407). After an initial planning, the context of use is specified, users and organizational requirements are gathered and based on those requirements and the creative intuition of the designer, a solution is produced. Finally the design is evaluated against the requirements before the cycle starts again.

User-centred design requires user involvement from "day one". The focus is on identifying the true needs of users and stakeholders. As these are difficult to formulate, usability tests, field tests and piloting as well as support during organisational implementation are undertaken. Only once having the chance to see and try out the (intermediate) results of the system design, can the users and stakeholders judge, whether the proposed system satisfies their true needs and concerns. The user-centered design methodology plays a dual role in our approach and in the contribution of this paper: we apply it for designing an instantiation of the proposed reintermediation framework in a concrete prototype and we use it as a feedback loop into overall design and verification of the framework and associated requirements for its implementation in practice.

\section{The problem space of travel disintermediation}

Market pressures and the threat of disintermediation

Few other industries have exploited the possibilities of ecommerce as readily as the travel sector. Being almost pure information goods at the point of purchase, virtually all information exchanges and transactions regarding travel products lend themselves readily to be effected online (Anckar and Walden, 2000). The pervasive availability of direct interaction channels with sellers and easy access to information sources on the Internet allow customers to choose from a rich variety of choices and bypass intermediaries offering little added value (Dilts and Prough, 2002).

Accordingly, the threat of disintermediation has become especially acute for offline travel agencies (Dilts and Prough, 2002; Anckar, 2003). Not only have a range of actors on the supply-side introduced e-commerce services for direct customer transactions (e.g. airlines, tour operators), but novel players have appeared in form of Internet-only travel marketplaces allowing direct information exchange and transactions between buyers and sellers (e.g. Expedia, Travelocity). Such "cybermediaries" (Giaglis et al, 1999) have leaner cost structures, global reach and technologicallyenabled economies of scale (large volumes at low transaction costs), unparalleled by the traditional business models of brick-and-mortar travel agencies. As a result of their attempts to optimize their cost-efficient value chains, the travel market has become a highly commoditized market with a wealth of easily accessible standardized products at low transaction costs and with price as the main differentiation criterion (Dilts and Prough, 2002).

In such a travel market, product and transport providers (e.g. airlines) do not protect their traditional distribution channels any more, forcing travel agencies to change their business models and explicitly charge their customers for their booking services. This makes them even more vulnerable to online competition as they are forced to expose and justify their fees. Large travel companies increasingly skip travel agencies and offer their packages directly online (e.g. TUI). The information quality of their web information is commonly at least as high as that of their catalogues. This not only overrides the traditional transaction processing role of travel agencies but also questions their information brokering purpose (Dilts and Prough, 2002).

Organizational constraints and customer requirements

The action scope of travel agencies is also determined by a number of external and internal organizational constraints which further question their traditional information and 
transaction brokering role. On one hand, information on travel destinations is freely available not only from professional online sources but also as user-generated content in travel communities in the form of online forums and wikis (Prestipino and Schwabe 2007). Studies have shown that the information quality of such user-generated content can be as high or even higher than professional content (Prestipino et al., 2006; Aschoff et al., 2007).

In addition, professional content of single travel providers often cannot parallel the richness of online content from third-parties (e.g. Google Maps, Google Earth and photo communities). Rating systems based on end-user evaluations help to build trust in Internet offerings (e.g. hotel quality rating platforms such as holidaycheck.de include commercial hotel descriptions and photos from hotel operators together with ratings, photos and vacation videos from actual hotel visitors). Such availability not only constrains the traditional information brokering role of travel agencies, but also increases customer expectations on the quality and versatility of information - which traditional agencies cannot parallel without themselves resorting to free Internet sources.

On the other hand, while the travel market in general has become highly commoditized, customers are increasingly demanding personalized offerings of travel products and services (Schmidt et al., 2008). Thereby, in addition to pragmatic needs (information, convenience, orientation against information overload), emotional needs (e.g. sense of security, unique experience, personalised advisory) also play an important role (ibid.). The physically collocated setting of traditional advisory carries chances to provide added-value by better satisfying these needs. Face-to-face interaction allows for richer communication and better understanding of the customer. This is especially true for frequently vague vacation needs which are difficult to be explicitly described beforehand (cf. sticky information (von Hippel, 1993)). Direct contact also conveys an emotionally higher sense of security and furthers the development of a trusted relationship, in contrast to the anonymity of the Internet setting.

As a result of all these factors, neither traditional destination information brokering, nor transaction processing services (against supplier-based commission fees), nor simple expansion into online sales channels are viable business models and value propositions for travel agencies any more ${ }^{1}$. In order to survive and keep customers, travel agencies need to develop reintermediation strategies (Giaglis

\footnotetext{
${ }^{1}$ In 2007 the tipping point of the travel market has been reached: the percentage of online travel bookings in the U.S. has surpassed the percentage of offline bookings with forecasts expecting further continuation of this trend (PhoCusWright, 2007).
}

et al., 1999) which allow them to assert value-added propositions that differentiate them from pure cybermediaries. A typical case is the introduction of multi-channel approaches which expand the sales and advisory offerings to online channels and call-centers (Schmidt et al., 2008). This is often accompanied by online transactions and marketing and strategic cooperations with complementary forms of cybermediaries (e.g. online marketers, travel communities) (Dilts and Prough, 2002). Though such approaches provide some leverage against pure Internet competition, they do not suffice for realizing a sustainable and flourishing business model as the diminishing market share and tumbling profits of offline travel agencies demonstrate ${ }^{1}$.

Above all, the introduction of pure online diversification strategies does not consider the intrinsic limitations in achievable value creation through online channels posed by organisational constraints of traditional travel agencies (Table 1). Due to reliance on human-mediated advisory service and its provision in direct physically collocated agent-customer interaction, the cost structures of brick and mortar travel agencies are much higher and more rigid than those of their online counterparts. This makes it impossible to achieve the same kinds of profit margins as pure cybermediaries.

Similarly, while supplier-based commission fees and promotions may still be obtainable from product suppliers, their extremely low margins can only be offset through large enough volumes of transactions, which cannot be efficiently realized through human-mediated services. In consequence, travel agencies cannot compete in a market of commoditized travel products where competition is based on price and profits are gained from large volumes of lowcost sales transactions of standardized products and services (Dilts and Prough, 2002). But the availability of highly standardized products at cheap cost has also heightened the customers' price sensitivity. This makes value propositions emphasising price vs. quality ratio increasingly difficult to realize. The implementation of a customer-fee revenue model forced by the absence of supplier-based commissions becomes very difficult in such conditions.

This pushes the travel agencies increasingly in the direction of having to differentiate their product offerings from the offerings available from Internet competition, while at the same time depending on the same product supply network (hotels, tour operators, airlines etc.). Such a combination of business pressures and organizational constraints (Table 1) points to the need for differentiation strategies not at the product but at the service level, such as the provision of highly personalized product and service packages involving high quality information and advisory services. This again places additional organizational constraints and intensifies the cost burden through dependency on qualified personnel and the necessity of making the 
Table 1 Problem space of travel disintermediation

\begin{tabular}{|c|c|c|c|}
\hline & Market pressures & Organizational Constraints & Customer Requirements \\
\hline \multirow[t]{3}{*}{ External } & $\begin{array}{l}\text { Elimination of supplier-based } \\
\text { commission fees }\end{array}$ & $\begin{array}{l}\text { Dependency on partner network for product supply } \\
\text { (e.g. hotels, tour operators, airlines, rentals) }\end{array}$ & Price vs. service quality ratio \\
\hline & $\begin{array}{l}\text { Commoditization of the travel market } \\
\text { (standardized products, price-based } \\
\text { competition) }\end{array}$ & $\begin{array}{l}\text { Availability of free third-party information on travel } \\
\text { products and services (professional + user- } \\
\text { generated content) }\end{array}$ & Information quality and versatility \\
\hline & $\begin{array}{l}\text { Large-volume, low-cost sales } \\
\text { transactions }\end{array}$ & & Trustworthiness of information \\
\hline \multirow[t]{3}{*}{ Internal } & Customer-fee revenue model & $\begin{array}{l}\text { Value creation through human-mediated advisory } \\
\text { service }\end{array}$ & $\begin{array}{l}\text { Satisfaction of pragmatic needs } \\
\text { (convenience, price) }\end{array}$ \\
\hline & $\begin{array}{l}\text { Multi-channel operation costs (travel } \\
\text { office, call-center, Internet) }\end{array}$ & $\begin{array}{l}\text { Direct customer interaction in a physically } \\
\text { collocated setting }\end{array}$ & $\begin{array}{l}\text { Satisfaction of emotional needs } \\
\text { (unique experience, personalised } \\
\text { offerings) }\end{array}$ \\
\hline & $\begin{array}{l}\text { Sales of personalized product and } \\
\text { service offerings }\end{array}$ & Personnel-intensive cost structure & Trustworthiness of agency \\
\hline
\end{tabular}

unique value proposition so explicitly perceivable and convincing for the customers, that they are willing to accept additional fees for the provided advisory service.

\section{A reintermediation framework for brick-and-mortar travel agencies}

Accordingly, we argue that rather than fighting the Internet competition on their own turf, brick-and-mortar travel agencies need to build new value propositions based on their core competencies, which distinguish them from the Internet competition: their close relationship to the clients and their expert-mediated advisory services. In doing so, they can build on current weaknesses of the Internet: Internet information is fragmented, it takes a significant amount of time to find good information even for experienced travelers, the configuration of highly personalized products is extremely time consuming and the trustworthiness of many sources can still not be verified.

At a first glance, this could suggest that there may be a future role of travel agents as a new kind of information brokers, guiding users through product offers on the Internet. Yet, this model based on the brokering concept alone is likely to be short-lived, as in such a scenario travel agencies increasingly find themselves competing against specialized e-tourism intermediaries (Buhalis and Licata 2002), search engines and information gatekeeper companies (e.g. Google et al.), which are providing ever more sophisticated and effective information search, aggregation and brokerage services.

In contrast, we propose that traditional travel agencies should focus on finding ways to use their essential organizational capabilities not as a hurdle but as a unique point of advantage: the creation of personalised travel offerings through a human-mediated advisory in direct agent-customer interaction in a physically collocated setting. To guide the concrete realization of such reintermediation strategies, we propose a framework based on the integration of kernel theories from information seeking behavior, interactive value creation, relationship marketing and the design of hedonic information systems.

The proposed reintermediation framework is depicted in Fig. 2. The solution space is organized along two main dimensions: (1) the differentiation between customer needs and organizational requirements and (2) the differentiation between pragmatic and emotional aspects. By mapping the solution space along these two axes we can take advantage of main aspects of the problem space as guiding lines for the search of appropriate artifact configurations in the solution space (Hevner et al., 2004). The identification of relevant aspects of selected kernel theories and their integration into a solution framework then allows us to identify theoretically-grounded meta-requirements (Walls et al., 1992) for the design of information systems implementing concrete instantiations of the proposed model in

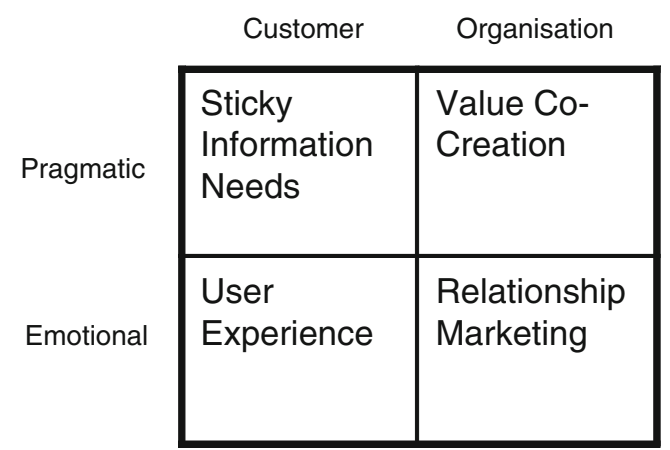

Fig. 2 Reintermediation framework for collocated travel advisory 
practice. The next sections discuss the components of the proposed framework.

\section{Sticky information needs}

The first component addresses the problem of effectively eliciting and satisfying inherently vague and implicit customer needs. Tourists are frequently not able to exactly formulate their demand, but rather express vague needs based on general feelings and desires (Prestipino et al., 2006). Only once they are presented with the information corresponding to their existing but unexpressed interests, they recognize that it fits their needs in the first place. This problem, also known from other domains (e.g. new product development) is commonly referred to as sticky information (von Hippel, 1993).

Examples for such ill-defined information needs are common requests for information in questions of members of online travel communities (e.g. looking for a sunny place in Europe). Finding an answer to such a need by consulting a classical guidebook or an Internet search engine would be difficult. Instead, by putting a natural language question to a travel community the user not only gets relevant answers for a vaguely formulated need, but also obtains additional relevant information, which he did not realize as part of his information need before (e.g. chilly water temperatures in an answer to the above example). In fact, a face-to-face dialogue would be even more useful than written communication in such a situation.

Expressing an information need is a particularly difficult issue when users are confronted with an information product, such as a travel catalogue, a travel guide book or an Internet search engine. In all these cases, users cannot express their information need effectively until they know what the possible answers look like and what terms are relevant in the first place. Theories of information seeking behaviour refer to this problem as the "anomalous state of knowledge" (Belkin et al. 1982), depicted in Fig. 3.

This perspective conceptualizes the information seeking problem space with respect to three main elements: the objective information need (actual user need), the need expressed and the available information. In a typical problem situation the expressed information need is only a portion of the actual, objective information need which therefore cannot be fully satisfied. And even for an expressed user need which would completely coincide with the objective information need, the required information simply may not be available. Furthermore, as the available information influences the user's capability of formulating an information need, the overlap between the expressed and objective need changes with available information.

Accordingly, rather than simply making information available, travel agents should focus on helping customers

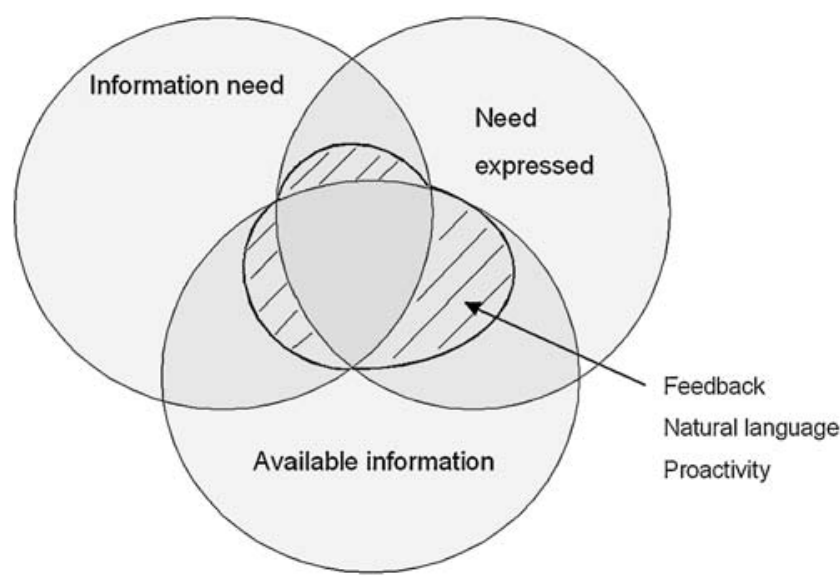

Fig. 3 The relationship between objective information need, expressed need and the available information (Prestipino and Schwabe, 2005)

to recognize and match the "objective information need" with the expressed need. Natural language information services offered by human consultants may increase the overlapping area in comparison to direct access to an information product: humans can be empathetic, proactive and can use the appropriate (im)precision and richness of natural language to query, give feedback and ask for clarification. Thus, in contrast to common assumptions of the superiority of the Internet as information channel, expert-mediated travel advisory in a collocated setting may offer unique added value to the customers if it succeeds in helping uncover and satisfy the customer's "hidden" (i.e. not explicitly expressed) information needs.

The role of user experience

The second element concerns the emotional dimension of customer needs. On the one hand, the travel advising process is highly emotionally coloured - customer criteria can rapidly change based on impressions of presented alternatives: a terrific photograph, a compelling video or a funny anecdote can easily shift customer desires and create emotional responses. The problem-solving process is intertwined with an emotional dimension of the advisory experience: desires are stirred, moods awaken and in this situation a decision process is carried out (Novak et al., 2008).

In addition, the increasing demand for personalized offerings (Anderson, 2006) and the vanishing separation of customer perception between material goods and services has shifted the focus of user value perception from pure product features to the accompanying services as critical source of differentiation (Reichwald and Piller, 2006). Such differentiation increasingly depends not only on what services are provided, but how they are made available to the customers, especially in the travel sector (Schmidt et al., 2008). 
The heightened importance of user experience in the usage of digital media (e.g. iPod/iPhone) also requires a change of stance in the design of information systems facilitating access to and consumption of such goods. Rather than being framed solely based on their utilitarian function, they need to be conceived with respect to hedonic aspects: not only in terms of user efficiency in fulfilling their task (e.g. finding a desired song or a suitable travel offer) but also in terms of user enjoyment in the process (Hassenzahl, 2002). Previous work has shown the importance of hedonic aspects for the design of information systems when these mediate the satisfaction of essentially hedonic user needs (e.g. finding movies to watch; Heijden, 2004). This is just the case in travel advisory, since underlying user motivations for searching for travel products and undertaking a vacation are intrinsically hedonic in nature (e.g. enjoyment, relaxation, adventure).

Accordingly, providers offering services which make the travel information seeking process an enjoyable experiencerather than a time consuming one of shifting through loads of impersonal information - are likely to achieve higher customer satisfaction. While multimedia on the Internet provides possibilities to address this challenge, travel agencies as real spaces can use the same means in a much more impressive and effective way, with human advisors adding a personal, human touch to the process.

\section{Value co-creation}

Though showing possible advantages in human-mediated information seeking and enhancing the hedonic user experience, the above considerations still remain within the traditional framing of the travel agency as the provider and the customer as the passive consumer of travel advisory services. In contrast, the pervasive availability of easy-touse Internet tools and services for information sharing, interaction and communication (e.g. wikis, blogs, instant messaging, online social networks) has profoundly transformed the role of end-users from passive consumers to active co-creators of content, products and services in commercial value networks (von Hippel and Katz, 2002; Bowman and Willis, 2003; Reichwald and Piller, 2006; Nov, 2007).

This exposes companies to growing pressure to increase the perceived value of their offerings by introducing cooperative business models in which end-users are empowered to active co-creators of value (Freedman, 2007). In contrast to traditional business models where information asymmetry is the fundamental principle of rentseeking (providers having more or better information than customers), in cooperative business providing equal access to information resources to all parties involved is the key mechanism of value creation (ibid.).
Accordingly, rather than insisting on the traditional view of expert advisors as the sole source of authoritative information, travel agencies should embrace the active, empowered role of the user from the Internet model. One way of doing this is to apply the principle of information symmetry to create an open setting in which the customer and the agent jointly work on configuring an individualized product or service offering matching previously inaccessible customer needs.

In line with the discussed information needs model, users are commonly not in a position to explicitly describe their needs and desires beforehand (e.g. before actually seeing or trying out a product) and to express them in terms suitable for integration in a company's product design. This makes the transaction costs of elicitating and transfering such "sticky" knowledge very high (von Hippel and Katz, 2002). One way of overcoming this is to actively involve customers in solving tasks in the product design process (e.g. product feature configuration), so that their implicit needs and preferences are directly embedded into the product configuration, as reflected in their choices. This makes such value co-creation models and strategies (Reichwald and Piller, 2006) an important element of satisfying pragmatic organizational needs of incorporating sticky knowledge of user preferences into the design of personalized product and service offerings.

\section{Relationship marketing}

The main premise of such a cooperative approach is that it can result in higher benefits for both parties: products better matching personal needs and desires for the customers and customer loyalty and sales growth ensuring sustainable business for companies. Thus, an important means of achieving competitive advantage for travel agencies compared to pure Internet intermediaries is to leverage their direct customer contacts to build more effective and stronger relationships. Such focus on more intensive interaction and cooperation between customers and producers is at the core of relationship marketing (Ivang and Sorensen, 2005).

Rather than employing product features and pricing as the main levers of customer choice, the focus here is on creating relationships with high levels of interdependence between customers and providers, as a means of reducing transaction costs, creating high quality offerings and keeping low the costs of governance (ibid.). In contrast, in transaction marketing, customers benefit from independence of their choice in choosing the best partner at any given decision point, regarding self-interest match and cost efficiency. Lowest cost purchases are reached through bargaining and bidding between competing providers and in conflict-based competition between the provider and the 
customer, satisfying their self-interest at the expense of each other (e.g. obtaining highest possible quality at lowest possible cost for the customer vs. obtaining highest possible price at lowest possible quality for the provider).

The relationship marketing stream proposes to overcome this classical buyer-seller conflict by means of negotiation and joint decision making, aiming at realizing sustainable win-win business models. The unique value proposition is the problemsolving capability (present and future) of the provider for the customer. The customer realizes benefits not only from the product itself but from the accompanying service reflecting the general competence of the provider which in turn improves the competitiveness of the customer (ibid.) and motivates him to develop loyal relationships and pay premium prices.

Thus, while transaction-marketing is a feasible choice for Internet travel intermediaries, relationship marketing is a more suitable model for traditional travel agencies. Pure Internet intermediaries can leverage the Internet channel to increase transaction efficiency and use pricing as the main lever of customer choice thanks to lean cost structures and large volumes of standardized transactions. Due to the difference in cost structures, transaction complexity and customer-fee revenue model traditional travel agencies cannot compete on these terms. Rather, a more suitable strategy is to use relationship marketing to ensure customer acceptance of higher priced personalised products and explicit commission fees for provided advisory services.

\section{Instantiation requirements}

\section{Meta requirements}

The main consequence of the proposed reintermediation framework is that a more sustainable value proposition and business model for traditional travel agencies should be based on leveraging their physical presence to provide value-added advisory services and on building more interactive and cooperative relationships with their customers. In particular, they should actively support travellers in expressing their hidden information needs and help them to satisfy them by creating highly individualized product configurations and heightening the user experience in the process.

To this end, travel agencies should reconfigure the advisory process as a highly iterative process, occurring in a dialogue between two parties with equal and transparent access to all relevant information resources, in a setting of cooperative interaction and joint problem-solving. Its success will depend on the capability of the agent to effectively moderate such an advisory process ${ }^{2}$ and on the availability of information in sufficient quantity and quality.

\footnotetext{
${ }^{2}$ An important issue beyond the scope of this paper.
}

The shared information resources aimed at eliciting and satisfying objective user needs should not only be correct, up-to-date, trustworthy and complete (see information quality criteria in (Prestipino 2008)), but they should also be rich enough to capture the imagination of the user and actively involve him in the problem description and solution seeking process. This should allow the customers' hidden information needs to surface, be comprehended both by the agent and the user himself and be related to the space of possible solutions - out of which a personalized configuration can be jointly constructed. The entire process should be designed in an open and stimulating environment, facilitating the development of trusted relationships and involving the user in an engaging experience.

\section{Design requirements}

Design requirements were defined in a twofold way. On the one hand, the meta design requirements were broken down into concrete terms relevant for the design of an interactive system. Second, to gather user-centred requirements, a web survey of customer information needs in travel planning ( 60 respondents), a workplace study and interviews with customers and travel agents in two travel agencies were undertaken. The resulting requirements are depicted in Table 2. The survey results suggest that travel information should primarily be based on location and price information which were determined as the most important features (47,4\% very important, $50,8 \%$ important for location; $35,1 \%$ very important, $47,4 \%$ important for price), followed by hotel comfort ( $22,8 \%$ very important, $52,6 \%$ important). They also indicate that travel agencies cannot rely on the brand of a tour operator to promote their destinations (40,4\% marginal, 43,8 \% unimportant). The workplace study and interviews both showed that travel agents primarily rely on catalogue information to convey information on tourist destinations while computers are largely used only for transaction information and processing (availability, cost, booking; Aggeler, 2007).

But catalogues are ill-suited for this purpose as they convey only static, context-free extracts of the travel destination. As there is more and richer information

Table 2 Design requirements for framework instantiation

Design requirements

DR1. Shared visualization of the problem and solution space

DR2. Visualization of all information sources available to the agent

DR3. Integration of Internet information and user-generated content

DR4. Joint interaction with the system for both parties

DR5. Active exploration of the solution space by the customer

DR6. Use of multimedia resources in a visually impacting way

DR7. Natural and intuitive interaction 


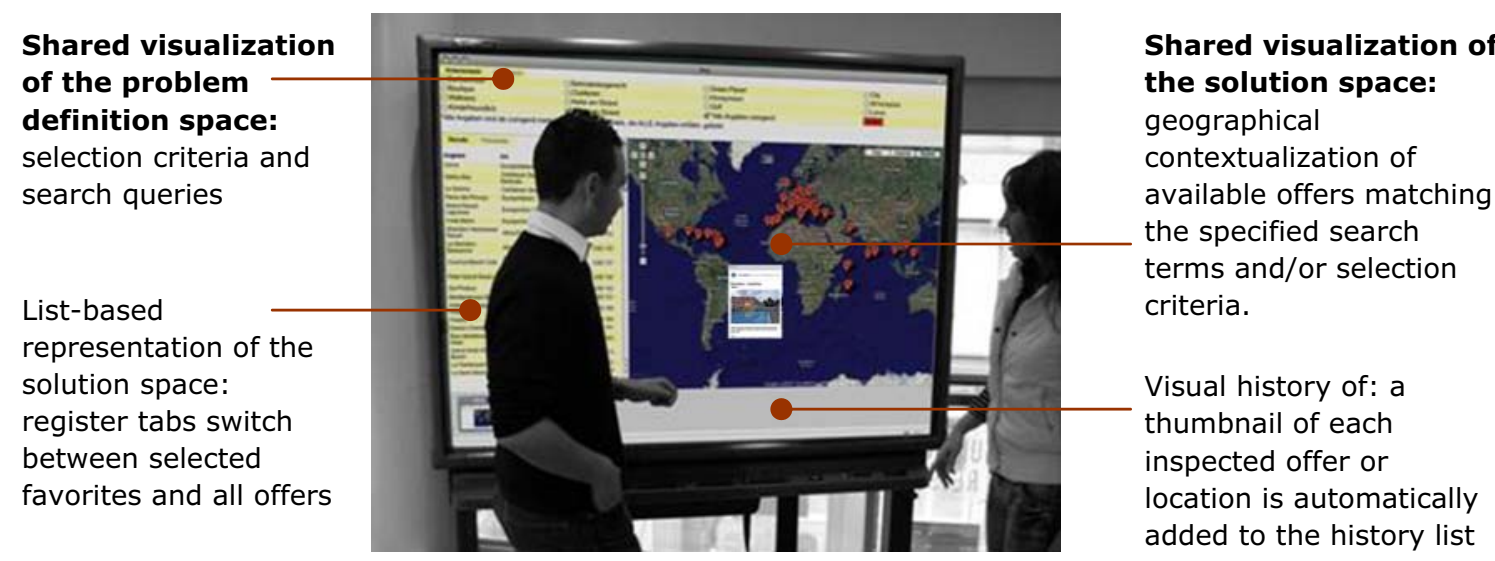

Fig. 4 A prototype instantiation of the proposed reintermediation framework: the SmartTravel system (Novak, Aggeler and Schwabe, 2008)

available on the computer than in the catalogue, an increasing number of customers are trying to look at the agents screen during an advisory session. Advisors then shift the screen, but the interaction remains inconvenient. There remains an intrinsic information asymmetry to the advantage of the agent in the literal sense of the principal agent theory (Eisenhardt 1989). This arrangement implies an inequality of roles, spurs distrust in the proposals of the agent and inhibits interaction - thus making effective collaboration difficult (Rodden et al. 2003; Scaife et al. 2002). Other shortcomings of the current support pointed out by the travel agents include the lack of a history of the advisory process (which would allow the agent to quickly continue the consultation in follow-up sessions), the need for more detailed destination information and the integration of Internet information sources with the official product database.

The above analysis leads us to following design requirements for information systems aiming at realizing the proposed reintermediation framework. In order to introduce a setting of cooperative interaction and joint problemsolving, a travel advisory support system should provide a shared visualization of the problem and solution space including all the relevant information resources. This should provide the customer with a shared view on the same resources as the travel agent so that the principal-agent conflict can be reduced. Transparent presentation of all available information to both parties should be realized in a way that reduces the information asymmetry, increases the process transparency and empowers the customer to an equal and active partner.

To satisfy customer demands on information completeness and versatility this should include information from third-party Internet sources and especially user-generated content from online travel communities. This in turn should increase the credibility of the agent and heighten the customer's trust in the consultancy. The system should enable the customer to proactively explore possible options of interest directly on the shared workspace so that the agent can discover otherwise hidden customer preferences by observing his exploration behaviour. The presentation of different alternatives and the possibility to act and explore information about possible destinations on one's own, should be realized in a way that entices customer's emotional involvement. This interaction should be realized in an intuitive and natural way. It should involve extensive use of multimedia resources in a visually impacting way in order to heighten user experience.

\section{The SmartTravel prototype ${ }^{3}$}

This section presents the realization of a concrete instantiation of the proposed reintermediation framework by implementing the described requirements into a proof-ofconcept prototype: the SmartTravel system.

The realization of the prototype is depicted in Fig. 4. As the basis for our design we chose a large interactive display providing a shared visual workspace that can be inspected jointly by both participants. Its visual qualities are also ideal for amplifying emotional impact. The interactive workspace consists of two areas: the shared problem definition space (product selection criteria and search queries) and the shared visualization of the solution space (visualization of matching results, history of user choices and favourites). This includes the visibility and shared manipulation of all information resources normally available only to the agent. The physical arrangement is such that the customer and the

\footnotetext{
${ }^{3}$ This is a revised and extended extract from our Work-in-Progress paper presented at CHI 2008 (Novak, Aggeler and Schwabe, 2008).

${ }^{0} \mathrm{http}: / /$ www.smarttech.com
} 
sales agent stand in front of a large board-like display. We opted for a touch-sensitive solution (a Smartboard ${ }^{4}$ ) as it allows the most natural interaction. It also allows natural coordination of access to the shared resource (pointing, gesture). We felt that such a setting introduces more equality between the parties and stimulates communication and interaction better than the "shoulder to shoulder" seating with a single mouse (Rodden et al. 2003).

In a typical use flow, the travel agent asks questions about customer's vacation needs and preferences and enters them directly as selection criteria into the problem definition space. The list of matching offers is also visualized on a geographical map (Google Maps) showing their geographical location. The customer can display more detailed information about offers which spur his interest or add interesting offers to his favourites, with all inspected detail pages automatically being saved in a visual history (Fig. 4). This supports a return to an interesting location during a consultation period and travel agents may use it to prepare follow up meetings.

The transfer of sticky information about customer needs into a personalized travel offer occurs through direct user involvement in the problem-solving process. By actively expressing the problem criteria and through direct exploration of possible solutions, the customer can identify options corresponding to his preferences without explicitly describing the criteria underlying his choices. Observing this interplay between options attracting customer's attention and his problem description, the travel agent can develop an understanding of implicit customer needs and propose viable solutions (Novak, 2009).

A special aspect of this solution is the integration of professional information travel agency databases as well as user-generated content from Internet travel communities (Fig. 5). In order to further emotional impact, the system incorporates access to multimedia material such as photos of travel destinations and user vacations as well as panorama videos (e.g. adventure trips, hotels). This fulfils several purposes:
1. Users from travel communities may provide information not available from other sources or not in the same quality (e.g. more up-to-date).

2. User-generated content may be regarded more trustworthy than professional information. The traveller knows that professional content is biased while contributions of community members are thought to be neutral (e.g. comments reflecting actual experiences, photos of locations in authentic conditions).

3. Professional catalogue information has to walk a narrow line praising offerings sufficiently to make them attractive while avoiding legal liabilities due to possibly false claims. User-generated content does not need to fulfil as strict legal obligations.

4. Multimedia presentation (photos, videos) on a large display has a great visual impact stimulating customer's emotional responses and providing an engaging experience.

The system architecture is based on a mashup architecture allowing the integration of different third-party applications (e.g. Google Maps) and data sources (e.g. travel agent database, online portals and travel communities). The client application is implemented with AJAX and can be run both as a standalone Smartboard application in the travel agency as well as a web-only application at the user's home PC. This opens up the space for additional scenarios such as follow-up consultations or remote advisory services.

\section{Evaluation in a field experiment}

\section{Evaluation method}

The proof-of-concept prototype has been evaluated in a controlled field experiment in a real-world travel agency. This evaluation served a two-fold purpose. On the one hand, it aimed at verifying the internal validity of the

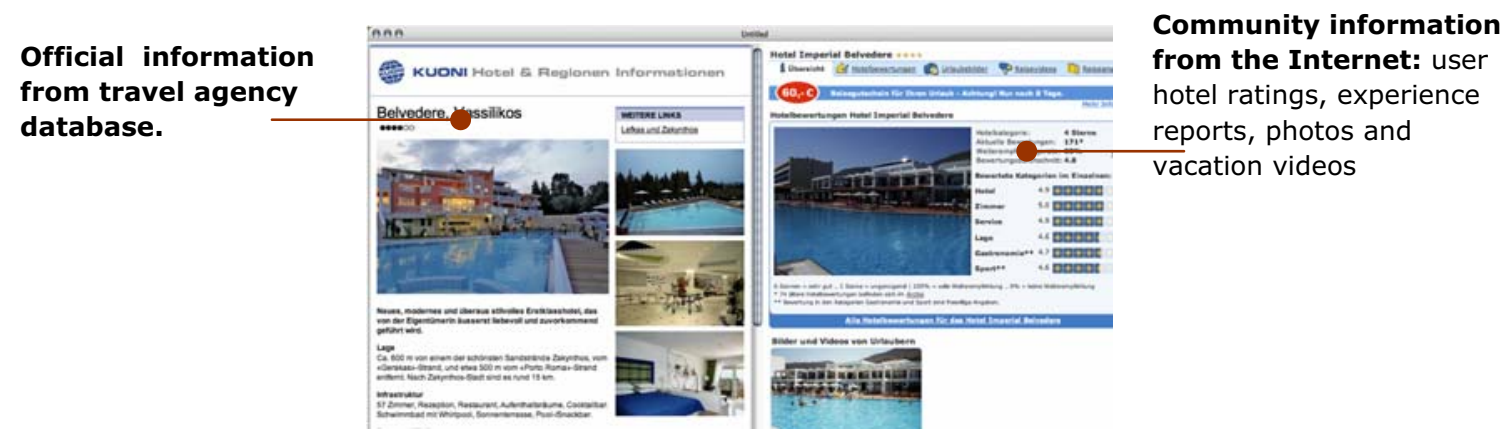

Fig. 5 Detail information from travel agency sources and Internet communities 
proposed reintermediation framework and the requirements for its realization as research contributions in their own. On the other hand, it also served as input to inform further design of the system into an improved instantiation, showing how the proposed framework can be even better implemented into practice.

As the developed prototype was the very first instantiation of the proposed solution framework and related design requirements, we opted for a controlled field experiment as a precursor to a pilot field study. To guarantee as realistic conditions as possible, we selected real customers and real travel advisors of a cooperating travel agency as test participants. Thus the prototype was submitted to use by real users in a realistic environment (real-world travel agency) with predefined tasks typically performed in a travel agency advisory session.

\section{Experiment setup}

Twelve customers from the travel agency client pool and four travel agents have been recruited as test participants on a voluntary basis. The customer sample was spread equally across different age groups (20-60 years) the majority of which declared high proficiency in computer use (67\%). The travel agents received a 30 min hands-on training in using the system. The customers received no prior training. They have been presented with the task of finding three suitable vacation offers for two different scenarios: a beach vacation and an adventure vacation. The experiment was based on a between-subjects design. All participants performed both tasks in two different settings: in a classical travel advisory setting (travel agent with PC, customer with print catalogue) and by using the SmartTravel system. The order of exposure to the two different settings and of the assignment of the two task scenarios was permuted. The time for task completion was limited to 30 minutes (typical duration of an advisory session). User feedback was collected through a structured questionnaire, in-situ observation and informal discussion.

The questionnaire was composed out of two main parts. One part implemented the unified theory of acceptance and use of technology framework (UTAUT) (Venkatesh et al., 2003) in order to verify the likelihood of acceptance of the proposed innovation by the target users (customers and travel agents). The other part elicited user responses to a direct comparison between the SmartTravel advisory and the traditional setting. It also examined more specific usability issues and user attitudes to individual functionalities of the system. This aimed at verifying the impact of specific prototype functionalities that correlate closely with individual elements of the proposed reinterme- diation framework and the design requirements for its instantiation in practice. This part also contained questions for informing improvement of the concrete prototype system for future practical use. In both cases user attitudes were elicited on a five-point Likert Scale. Presenting the complete questionnaire is out of scope of this paper. In the following section we discuss only the most important results relevant for the validation of the presented reintermediation framework and its concrete instantiation in the SmartTravel prototype.

\section{Evaluation results ${ }^{5}$}

Perceived added-value, task-adequacy and intention to use

The results of a direct comparison with the traditional advisory setting suggest that both customers and travel agents perceive a significant added-value of the advisory service with SmartTravel: $83.3 \%$ of customers and three out of four agents reported a preference for SmartTravel as a better travel planning method (Fig. 6) (Novak, Aggeler and Schwabe, 2008). This is further confirmed by the very high and much better task adequacy of the proposed system with respect to the traditional advisory setting: $83.3 \%$ of users reported a high $(41.7 \%)$ to very high $(41.7 \%)$ adequacy of available means for task completion with the SmartTravel system, compared to only $41.7 \%$ of high adequacy judgments for the traditional setting (Aggeler, 2007).

Attitudes of travel agents to perceived system benefits (performance expectancy measured by the UTAUT model) also point to positive task adequacy and usefulness of the system: three out of four agents found the system very useful for their job while two out of four explicitly attested increased productivity, quicker task completion and simplification of work. Finally, the difference in the reported intention of using the two different advisory settings rounds up the picture: not only have all but one customer $(91.7 \%$, one without answer) reported that they would like $(25 \%)$ or very much like (66.7\%) to use the SmartTravel system in the future, but also a third of them were explicitly negatively oriented towards future use of the traditional advisory setting (Fig. 7).

Such results indicate that customers clearly perceived a significant added-value in the application of the SmartTra-

\footnotetext{
${ }^{5}$ In Novak, Aggeler and Schwabe (2008) and Schwabe, Novak and Aggeler (2008) we presented parts of these results in terms of general usability, interaction design aspects and user acceptance of the SmartTravel system in its own right, not relating them to the proposed reintermediation framework. In Novak (2009) we discussed specific issues concerning the principal-agent problem, also not the subject of this paper.
} 


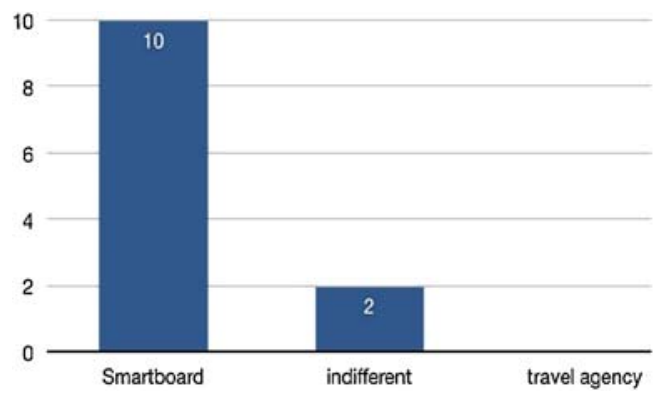

Fig. 6 Customer preference of SmartTravel supported vs. classical travel advisory

vel system for travel advisory compared to the traditional setting. This demonstrates that a given system design and its implementation in a concrete prototype are adequate for achieving the original goal of providing new added-value propositions for collocated travel advisory. Accordingly, since the system was build as an instantiation of the proposed reintermediation framework, this shows that the elements of the framework are not in contradiction to each other and can be successfully integrated and implemented into a system usable in practice (cf. utility criterion for design-science research (Hevner et al., 2004). Following the design-science (ibid.) and piloting research methodologies (Witte, 1997) this confirms the internal validity of the proposed framework.

Qualitative feedback and a closer inspection of results for individual system functionalities more specifically related to individual elements of the framework further consolidate this conclusion. Since abstract framework elements are operationalized through meta-requirements and design-requirements (see Table 3) we can also test the framework by considering to which extent the concrete implementation of these requirements was appreciated by target users. Thereby, while some meta-requirements can be directly tested from explicit user feedback (e.g. user experience), others can only be implicitly verified through associated design requirements or indirect observation of user behavior (e.g. the extent to which sticky information on customer needs was effectively obtained). By considering qualitative feedback we can also better understand the findings of the questionnaire data.

MR1 and MR3: Elicitation of implicit needs/active customer involvement

The extent to which the surfacing of sticky information on implicit customer needs was successful as well as the extent of active customer participation in the co-creation of personalised solutions are hard to measure quantitatively. They can be observed and reasoned upon based on user comments on their use of the system. Customer feedback highlighted the possibilities of easily showing and discussing different solutions (DR4, DR5) and the quick iteration through and saving of different solutions (Aggeler, 2007).

The agents particularly pointed out the helpfulness of having an interactive overview of the solution space as a visual reminder of available solution options and for enticing proactive user input (customers bringing up options and preferences which agents themselves hadn't noticed). Especially the overview provided by SmartTravel was found superior to the classical setting $(66.7 \%$ very good and $33.3 \%$ good vs. $33.3 \%$ good and 66.7 neutral or negative assessment).

The same holds for the available means of expressing user needs (Novak, 2009): both regarding the ease of search based on desired criteria (83.3\% positive or very positive, $16.7 \%$ undecided for SmartTravel vs. $58.3 \%$ positive or very positive, $16.7 \%$ undecided and $25 \%$ negative for the classical setting) and regarding the usefulness of available criteria of product selection (91.7\% positive or very positive, one w/o answer for SmartTravel vs. $58.3 \%$ positive, $16.7 \%$ undecided and $25 \%$ negative for the classical setting).

\section{MR2: Information transparency and trustworthiness}

The shared visualization of the problem and solution space for both parties (DR1) and the ability of active exploration by the customer (DR2) were greatly appreciated by both customers and agents. Not only was the visual overview of the solution
Fig. 7 Intention to use the system

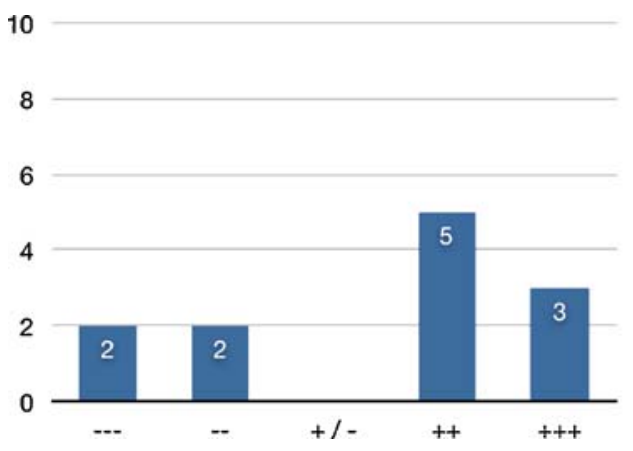

Classic travel agency

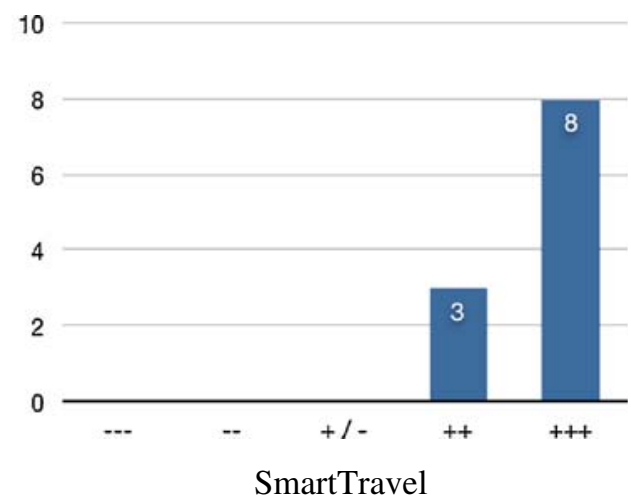


Table 3 Meta requirements for framework instantiation

\begin{tabular}{|c|c|c|}
\hline \multicolumn{3}{|c|}{ META REQUIREMENTS } \\
\hline MR1. & \multicolumn{2}{|c|}{ Support the elicitation of implicit customer needs (sticky information) } \\
\hline MR2. & \multicolumn{2}{|c|}{ Provide for information transparency and trustworthiness } \\
\hline MR3. & \multicolumn{2}{|c|}{$\begin{array}{l}\text { Involve the customer as active participant the cooperative problem-solving } \\
\text { process }\end{array}$} \\
\hline MR4. & \multicolumn{2}{|c|}{ Stimulate the establishment of a trusted customer-agent relationship } \\
\hline MR5. & \multicolumn{2}{|c|}{ Stimulate emotional involvement of the customer } \\
\hline MR6. & \multicolumn{2}{|c|}{ Provide an engaging experience } \\
\hline \multicolumn{2}{|c|}{ STICKY INFORMATION NEEDS } & Value Co-Creation \\
\hline \multicolumn{2}{|c|}{ MR1, MR3 } & MR1, MR2, MR3 \\
\hline \multicolumn{2}{|c|}{ UsER EXPERIENCE } & RELATIONSHIP MARKETING \\
\hline \multicolumn{2}{|c|}{ MR5, MR6 } & MR2, MR4, MR5 \\
\hline
\end{tabular}

space greatly appreciated by the users but the quality of the information overview has been assessed notably higher for SmartTravel (83.3\% very good, $16.7 \%$ good) than in the classical setting $(8.3 \%$ very good, $50 \%$ good, $16.7 \%$ undecided and $25 \%$ negative). The availability of all information sources available to the agent and the integration of third-party Internet information were also appreciated by the customers and were considered more trustworthy in SmartTravel (MR2). All customers attributed high (50\%) to very high $(41.7 \%$, one w/o answer) trustworthiness of information in the SmartTravel setting as opposed to negative $(25 \%)$ and low positive valuation in the classical setting (only $16.7 \%$ high). This is attributed to transparency ("I see what the agent sees") (DR1, DR2) and inclusion of user-generated content from Internet travel portals (DR3) i.e. the ability to assess product characteristics not only based on the statements of the sales agent and official travel information but also based on the reviews and ratings of other users (Novak, 2009).

MR4: Establishment of a trusted relationship

Given a one-off advisory session and its limited duration (30 min) we could not directly observe or measure the extent to which the new setting actually furthers establishment of close and trusted relationships. Though related aspects such as higher trustworthiness of information, the appreciation of the transparency of the situation and the active involvement of the customers may be interpreted as

Fig. 8 User experience
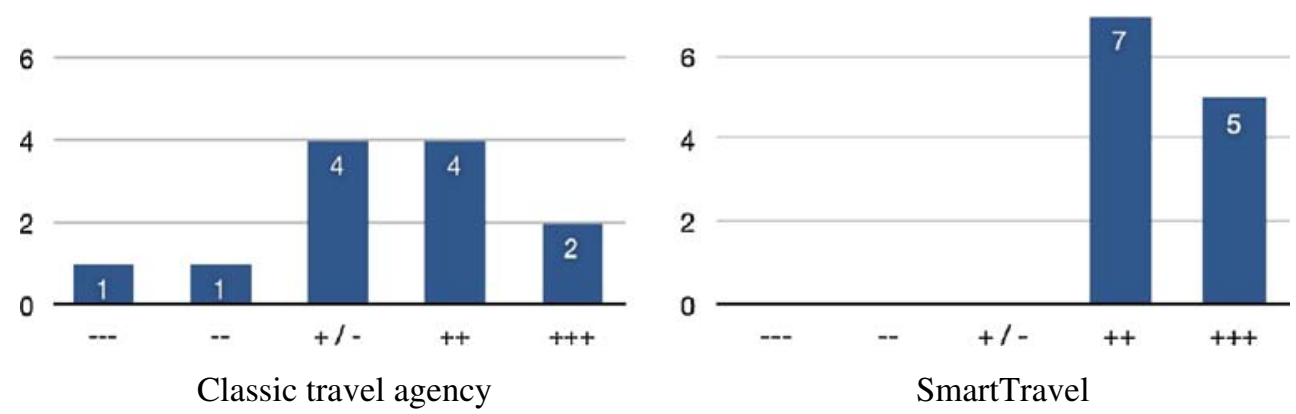
indirect indicators favouring the establishment of an appropriate relationship, this is an issue to be more specifically explored in further work.

MR5 and MR6: Emotional involvement/engaging user experience

User experience feedback (Fig. 8) shows an overwhelming preference for the SmartTravel advisory (58.3\% assessed the experience as good and $47.1 \%$ very good) compared to the classical setting (33.3\% good, $16.7 \%$ very good, $16.7 \%$ negative). In addition a great majority $(88 \%)$ found that the use of the system made travel planning more interesting than in the traditional setting.

Both travel agents and customers were delighted by the system. This was reflected in their reactions during the sessions, explicit statements in open-end questions and informal feedback in discussions. They loved the visual overview (DR1) on the large screen, the richness of multimedia information (photos, panorama videos) (DR6) and the natural touch-based interaction (DR7). Overall, we could observe a "wow"-effect, similar to the one reported by Rodden et al. (2003). Especially the use of multimedia information (explicitly confirmed by all users) and the sense of touch supported high emotional involvement ("bringing the sense of vacation closer") (MR6).

\section{Overall system usability}

The overall usability of the system as measured by constructs from the UTAUT questionnaire has been very positively assessed: almost all participants (customers and agents) found the system interaction clear and understandable (93\%), easy to learn (88\%) and easy to use (87\%). They liked using the system in general (88\%) with all participants (customers and agents) but one stating that they would like $(31 \%)$ or very much like to use the system in the future $(62 \%)$. User comments highlighted the familiarity of the interaction style due to the system being implemented as a standard web application. Critical comments referred largely to technical details such as that clicking by touch-tipping did not always work properly (calibration) and that click-paths to different aspects of community information (e.g. photos, vacation reports) were too long.

\section{Conclusions}

We have presented and evaluated a reintermediation approach for traditional travel agencies which allows them to develop new added-value propositions through novel forms of IT-enabled travel advisory services which integrate the advantages of interactive multimedia technologies and
Internet channels with the advantages of direct customer interaction in the physical agency setting.

Validity of results and limitations

Following the design-science methodology, the design and implementation of a concrete prototype system successfully satisfying the requirements of the proposed framework shows that the synthesis of proposed solution elements into a functioning system is possible. This demonstrates that the integration of the proposed elements of kernel theories is possible in a non-contradictory way (Witte, 1997; Schwabe and Krcmar, 2000). The verification in a controlled experiment in a pre-pilot setting indicates that given a specific problem situation (traditional travel agency), characterized by selected variables (value creation through human-mediated travel advisory service, physically collocated customer-agent interaction, customers requiring personalized travel products and services) the proposed innovation can be effectively realized.

The evaluation results also allow us to consider the second validation form of the piloting approach (Witte, 1997): given the successful realisation of the proposed innovation it induces specific technological, organizational or economic benefits, such as a new form of advisory service (cooperative process with proactive involvement of the customer) with clearly perceived added-value and higher user satisfaction compared to the traditional setting, higher trustworthiness and an engaging user experience. This suggests that by introducing a concrete implementation of the proposed framework we can expect such observed effects to actually occur in practice. Validating the extent to which these effects can indeed effectively ensure market success can be achieved only through introduction in everyday business practice.

Obviously, the small sample of test participants allows only limited generalization as does a controlled field experiment, compared to a regular pilot study of system use in everyday organizational practice, over a period of time. We do not claim the data to be representative of all users or agents. As in all first empirical studies of pilot systems, users may have been biased to please the observers or impressed by the novelty of the system. Such doubts can be verified by repeated tests with larger samples or pilot studies over a longer time. Fully generalizable data can only result from a more widespread usage in day-to-day business. As our cooperating travel agency has committed resources for further trials and a roll out of the prototype in real-world pilots in several travel agencies, we are optimistic to report such data in future publications.

Acknowledgements We thank STA Travel Switzerland and especially Jean-Philippe Spinas for their cooperation and support in the 
SmartTravel evaluation. We also kindly thank Mattias Aggeler for his contribution in the prototype system development and the first evaluation as part of his Master's Thesis supervised by the authors.

\section{References}

Aggeler, M. (2007). Konzeption und Exntwicklung eines kooperativen, multimedialen Erlebnisraumes für das Reisebüro der Zukunft, Master's Thesis, University of Zurich

Anckar, B. (2003). Consumer intentions in terms of electronic travel distribution, implications for future market structures. e-Service Journal, 2.2, 68-86.

Anckar, B., \& Walden, P. (2000). Destination maui? An exploratory assessment of the efficacy of self-booking in travel. Eletronic Markets, 10:2, 110-119.

Anderson, C. (2006). The long tail: why the future of business is selling less of more. New York: Hyperion.

Aschoff, F., Prestipino, M., \& Schwabe, G. (2007). Cooperation technology and timeliness of information: Comparing travelbooks, wikis and online communities. Proc. of the 15th European Conference on Information Systems (ECIS). Switzerland: St. Gallen, June 07-09.

Belkin, N.J., Oddy, R.N., Brooks, H.M., et al. (1982). ASK for Information Retrieval: Part I. Journal of Documentation, 38(2), 61-71.

Bowman, S., Willis, C. (2003). We Media-How audiences are shaping the future of news and information, The American Press Institute

Buhalis, D. (2002). Information Technology in Tourism: Information Technology for Strategic Tourism Management. Financial Times, Prent. Int.

Buhalis, D., \& Licata, M. (2002). The future eTourism intermediaries. Tourism Management, 23(3), 207-220.

Dilts, J., \& Prough, G. (2002). Travel agencies: A service industry in transition in the networked economy. The Marketing Management Journal, 13(2), 96-106.

Eisenhardt, K. (1989). Agency theory: An assessment and review. Academy of Management Review, 14(1), 57-74.

Freedman, J. B. (2007). What motivates voluntary engagement in cooperative information systems, Proc. of HICSS '07. Washington: IEEE Computer Society.

Giaglis, G. M., Klein, S., \& O'Keefe, R. (1999). Disintermediation, reintermediation, or cybermediation? the future of intermediaries in electronic marketplaces. Proceedings of the $12^{\text {th }}$ Bled International Electronic Commerce Conference. Slovenia: Bled, 389-407, June 7-9.

Hassenzahl, M. (2002). The effect of perceived hedonic quality on product appealingness. International Journal of Human-Computer Interaction, 13, 479-497.

Heijden, H. (2004). User acceptance of hedonic information systems. MIS Quarterly, 28(4), 695-704.

Hevner, A. R., March, S. T., Park, J., \& Ram, S. (2004). Design science in information systems research. MIS Quarterly, 28(1), 75-105.

International Organization for Standardization (1999). ISO 13407Human-centred design processes for interactive systems. http:// www.iso.org/iso/iso_catalogue/catalogue_tc/catalogue_detail.htm? csnumber $=21197$

Ivang, R., \& Sorensen, O.J. (2005). E-Markets in the battle zone between relationship and transaction marketing. Eletronic Markets, 15(4), 393-404.

Markus, M. L., Majchrzak, A., \& Gasser, L. (2002). A design theory for systems that support emergent knowledge processes. MIS Quarterly, 26:3, 179-212.

Nov, O. (2007). What motivates wikipedians? Communications of the ACM 50 11, 60-64. ACM Press.
Novak, J. (2009). Mine, yours...ours? designing for principal-agent collaboration in interactive value creation, proc. of wirtschaftsinformatik 09. Vienna: Österreichische Computer Gesellschaft.

Novak, J., Aggeler, M., \& Schwabe, G. (2008). Designing largedisplay workspaces for cooperative travel consultancy. proc. of chi 2008, extended abstracts and applications, work-in-progress. ACM Press.

PhoCusWright (2007). U.S. Online Travel Overview, PhocusWright Inc. http://www.phocuswright.com

Prestipino, M. (2008). Die virtuelle Gemeinschaft als Informations system-Informationsqualität nutzergenerierter Inhalte in der Domäne Tourismus. Zürich: Dissertation, Universität Zürich.

Prestipino, M., Aschoff, F., \& Schwabe, G. (2006). What's the use of guidebooks in the age of collaborative media? Empirical Evaluation of free and commercial travel information, Conference Proceedings 19th Bled eConference eValues. Bled, June 5-7.

Prestipino, M., \& Gerhard Schwabe, G. (2007). In T. Myrach, \& S.M. Zwahlen (Eds.), Neue Reiseinformation, neues Reisen. Virtuelle Welten? Die Realität des Internet. Bern: Verlag Peter Lang.

Prestipino, M., Aschoff, R., Schwabe, G. (2007). How up-to-date are online tourism communities? An empirical evaluation of commercial and non-commercial information quality, Proc. of HICSS - Hawaii International Conference on System Science, 40, Kona.

Prestipino, M., \& Schwabe, G. (2005). Tourismus-communities als informationssysteme. ferstl, o.; sinz, e., ecker, s., isselhorst, $t$ : eEconomy, eGovernment, eSociety-Proceedings der Wirtschaftsinformatik. Heidelberg: Physica.

Reichwald, R., \& Piller, F. T. (2006). Interaktive wertschöpfung. open innovation, individualisierung und neue formen der arbeitsteilung. Wiesbaden: Gabler Verlag.

Rodden, T., Rogers, Y., Halloran, J., \& Taylor, I. (2003). Designing novel interactional workspaces to support face to face consultations, Proc. of CHI 2003. ACM.

Scaife, M., Halloran, J., \& Rogers, Y. (2002). Let's work together: supporting two-party collaborations with new forms of shared interactive representations, Proc. of COOP'2002. IOS.

Schmidt, I., Schögel, M., \& Schulten, M. (2008). Nutzenbasierte Kundensegmentierung in Mehrkanalsystemen der Reisebranche. In B W. Wirtz (Ed.), Multi-Channel-Marketing.. Wiesbaden: Gabler.

Schwabe, G., Novak, J., \& Aggeler, M. (2008). Designing the tourist agency of the future, 21st bled econference on ecollaboration: overcoming boundaries through multi-channel interaction. Bled, June 2008.

Schwabe, G., \& Krcmar, H. (2000). In Piloting a Sociotechnical Innovation. Proceedings of the 8th European Conference on Information Systems ECIS 2000, Wirtschaftsuniversität Wien, Wien, 132-139.

Sheth, J.N., \& Parvatiyar, A. (1995). The evolution of relationship marketing. International Business Review, 4, 397-418.

Venkatesh, V., Morris, M. G., Davis, G. B., \& Davis, F. D. (2003). User acceptance of information technology: Toward a unified view, MIS Quarterly. Minneapolis.

von Hippel, E. (1993). Sticky information and the locus of problem solving : implications for innovation., MIT Alfred P. Sloan School of Management

von Hippel, E., \& Katz, R. (2002). Shifting innovation to users via toolkits. Manage Sci, 48(7)

Walls, J. G., Widmeyer, G. R., \& El Sawy, O. A. (1992). Building an information system design theory for vigilant EIS. Information Systems Research, 31, 36-59.

Werthner, H., Ricci, F. (2004). E-Commerce and tourism. Communications of the ACM, 47(12) December 2004

Witte, E. (1997). Feldexperimente als innovationstest-Die pilotprojekte zu neuen medien. $Z f b f, 49(5), 419-428$. 